\title{
Delay in initiating tuberculosis treatment and factors associated among pulmonary tuberculosis patients in East Wollega, Western Ethiopia
}

\author{
Tatek Wondimu, Kifle W/Michael, Wondwossen Kassahun, Sofonias Getachew
}

\begin{abstract}
Background: Delay in treatment is also likely to be associated with a greater number of secondary cases per index case.

Objective: to assess the length of patient and health system delays; and identify factors influencing these delays among pulmonary tuberculosis patients.

Methods: We conducted a cross-sectional study in 13 selected government health facilities that provide both diagnostic and treatment services using Directly Observed Treatment Short course (DOTS) program. Data were collected from pulmonary TB patients aged 15 years and above during their intensive phase of DOTS treatment using a semi-structured questionnaire.

Results: The median total delay was 90 days; with 28 days patient delay and 42 days health system delay. A large proportion $(63 \%)$ of the overall total delay was contributed by health system delay. Patients from urban areas were $46 \%$ more likely to present to health care providers than patients from rural areas, adjusted hazard ratio (AHR) of 1.46 ( $95 \%$ CI: 1.10 - 1.95). Patients from urban areas were $54 \%$ more likely to be diagnosed and start treatment earlier than patients from rural areas, AHR of 1.54 (95\% CI: 1.15-2.07). Female patients were more delayed to present to health providers than their male counterparts with AHR of 0.63 (95\%CI: 0.47-0.84) but had shorter health system delay than male patients with AHR of 1.51 (95\% CI: 1.1-22.04).

Conclusion: A greater proportion of the overall total delay was contributed by health system delay. The health system should be more accessible for the unmet need. New approaches to make health services more accessible to those in greatest need (rural and women) should be designed and developed. [Ethiop.J.Health Dev.2007;21(2):148-156]
\end{abstract}

\section{Introduction}

Late diagnosis of pulmonary tuberculosis is likely to be associated with a worse prognosis owing to the presence of extensive disease and poor clinical condition. Furthermore, of particular importance from epidemiologic perspective, delay in treatment for active tuberculosis is likely to be associated with a greater number of secondary cases per index case (1-6).

Patient's alertness to the symptoms of tuberculosis combined with health workers' readiness to diagnose the disease and understanding which factors influence this delay is crucial for controlling the spread of the infection within a community $(3-5,7)$. Evidences of related literature revealed that health system, community, family, and other personal issues are influencing factors for the effective health seeking behaviors and case findings. Individual ways of experience of own symptoms and illness, perceived causes and experiences with the health care system are some aspects of personal issues (3).

Paucity of any evidence on the magnitudes of delay components (patient delay, health service delay and total delay) and the factors associated with delay in careseeking behavior (patient delay) and diagnosis and treatment by health care providers (health system delay), among pulmonary tuberculosis patients were among the reasons to conduct this study.

\section{Methods}

A cross-sectional survey of pulmonary tuberculosis patients was conducted from January 11, 2006 to April 11, 2006 in 9 Woredas and one city administration in East Wollega Zone of the Oromia Regional State. Among a total of 18 health facilities in the zone that provide diagnostic and treatment services for DOTS, 13 were selected based on the average number of TB cases detected by the facilities per month in the previous year. Facilities were included in the study if they have detected 5 cases or more per month in the previous year.

All pulmonary tuberculosis patients (smear positive and smear negative) registered in the National $\mathrm{TB}$ and Leprosy Control Programme (TLCP) in selected health facilities and who were in their intensive phase of DOTS treatment were included in the study. Participants under 15 years of age on the day of start of treatment and those patients who were terminally ill and could not respond were excluded from interview. All eligible patients observed during the study period in the selected facilities for TB treatment were interviewed before transfer-out. Moreover, to avoid double counting, reminder note was attached with the referral sheet to the receiving health facility. However, at the beginning of the data collection, 11 patients were referred to facilities found outside the study area. As a result, data regarding the characteristics of these patients were not collected. 
After reviewing TB registry, leprosy and TB program coordinators from the respective health facilities were trained and then they interviewed eligible subjects using a semi-structured and pre-tested Amharic questionnaire. The study instrument was divided into five parts: (1) diagnosis and treatment information from the Tuberculosis Registry and TB treatment card, (2) demographic and socio-economic information, health seeking behavior (presenting symptoms, duration and place of contacts made), (3) geographic accessibility (distance and time to the nearest public health institution), (4) knowledge on the symptoms of tuberculosis, and (5) perception about the symptoms of disease and stigma associated with tuberculosis. In order to classify TB patients, the diagnostic and treatment algorithms were used according to the national tuberculosis prevention and control manual. Study subjects were asked specific questions to assess knowledge about signs, symptoms and causes of TB. Then a separate summary indicator was developed for analyses by dividing the total score into three strata, $\leq 25^{\text {th }}$ percentile ("unsatisfactory knowledge"), between $25^{\text {th }}$ and $75^{\text {th }}$ percentile ("average/fair knowledge") and $\geq 75^{\text {th }}$ percentile ("enough knowledge"). Severity of the disease upon first presentation among patients in the health facility was graded on a simple functional scale according to whether the subject could still do a full day's work, do some daily activities outside the house or was house or bed-bound. In this study, we mean by 'traditional health facility' those informal and/or unrecognized institutions or individuals providing health care services (this includes traditional healers, herbalists, spiritual healers etc.). On the other hand, all recognized health facilities including drug shops were regarded as modern.

Ethical approval was obtained from Jimma University Ethical Clearance Committee. Permission was sought from Zonal Health Office and the respective Woreda Health Offices and Health Facilities. Informed verbal consent was secured from every eligible tuberculosis patients before inclusion into the study. Privacy and confidentiality was ensured.
Respondents were first asked to estimate the time in days they had been experiencing cough or other symptoms before presenting to health facilities with the current diagnosis of tuberculosis (total delay). Local religious, political and agricultural events were used as a calendar to collect information for those patients who were unable to estimate the date of onset of first presenting symptoms for the current diagnosis (TB).

Data were entered into Epi-Info 3.3.2 version for windows (CDC, Atlanta, GA, USA) and validated. Then the data were analyzed by using univariate, bivariate and multivariate statistical techniques with the help of SPSS version 11 for windows.

As the most appropriate measures for describing the occurrence of events over time, rates of time delays in terms of person-days and the corresponding "hazard ratios" were calculated to compare different groups. In this analysis, a "hazard ratio" greater than 1 associated with a factor suggested an increase in the rate of presentation to or case detection by health services compared to the referent group.

The rate of presentation to health facility or start of treatment was calculated as, Rate $=e / d$ where $e$ is the number of events occurring over time (such as presentation to health institution or commencement of treatment) and $d$ is the total number of person days (see Table 1 for the specific calculations). Cox proportional hazards analysis was used to investigate factors that are predictive of delays.

Hazard ratios with 95\% confidence interval for both unadjusted and adjusted results were presented. Variables that showed significant association with time delays in the bivariate analysis were included in the Coxregression model. During regression modeling, p-value for the likelihood ratio $\leq 0.05$ was used for relevant variables in the final model. The "proportional Hazards" assumptions were checked.

Table 1: Formula for calculating specific rates (different components of delay)

Rate

"Total delay to anti-TB
treatment"
"Patient delay"
"Health service delay"

"Total delay to anti-TB

treatment"

"Health service delay" e (numerator)

$d$ (denominator)

\author{
Total person-days of coughing in the \\ community \\ Total person-days of coughing before first \\ presentation to a health institution \\ Total person-days of coughing between \\ first presentation to a health institution and \\ start of anti-TB treatment
}




\section{Results}

A total of 201 pulmonary TB cases were included from 13 health facilities during data collection period in the intensive phase of treatment. Three patients were excluded from the study ( 2 cases were aged below 15 years and 1 case was critically ill and unable to respond). A total of 198 pulmonary tuberculosis patients were eligible for this study. Only one male patient was unwilling to participate for the interview providing a response rate of $99.5 \%$ among the eligible patients.

Among the participants of this study, 111 (56.3\%) were females, $141(74.6 \%)$ found in the age group 15-35 years, $106(53.8 \%)$ reside in rural areas, $138(70.1 \%)$ were married, $68(34.5 \%)$ engaged in agricultural occupation, $102(52 \%)$ were non-educated, $175(88.8 \%)$ ere Oromo by ethnicity and $109(55.3 \%)$ protestant in religion. Mean age for male sex was 33.6 years $(\mathrm{SD}=$ 14.1), while it was 29.7 years $(S D=11.8)$ for females, significantly different between the two sexes (student $-t$ test, $\mathrm{p}=0.038$ ). The average monthly family cash income was 258.97 Eth. Birr. However, information on income was obtained from 155 subjects only. The median travel time to the nearest public health facility in a single trip was $1 \mathrm{hr}$ (Inter quartile range [IQR] $=1.5$ hours) and 0.33 hours ( $\mathrm{IQR}=0.25$ hours) for rural and urban patients respectively, with a statistically significant difference (Mann-Whitney U-test $=7.97, \quad \mathrm{P}<0.001$ ). Some characteristics of participants along with the distribution of delay are summarized in Table 2.

Clinical characteristics and health seeking behavior of the patients: Forty eight percent $(\mathrm{n}=95)$ of patients were positive for sputum AFB test, $182(92.4 \%)$ were new cases. Relapse and default cases constituted 3.6\% each.

At first presentation to health service providers, $82.2 \%$ $(n=162)$ of the patients reported to have cough of 3 weeks or more, chest pain $58.9 \%(\mathrm{n}=116)$, cough with blood stained sputum $43.7 \%(\mathrm{n}=86)$ and shortness of breath $53.3 \%(n=105)$. The majority, $95.9 \%(n=189)$, of the subjects presented with one or more of the above chest symptoms. Significant difference was not observed in time to presentation or initiation of treatment with all the symptoms after examining the symptoms separately or in groups.

In general, $35.6 \%$ of patients reported first to drug shops, private clinics or private hospitals upon recognition of symptom. Forty three percent of the patients reported first to either health centers or government hospitals.

Patients reporting first to traditional/spiritual healers constituted $4.1 \%(n=8)$. The median total delay from noticing symptoms to commencement of treatment seems higher (105 days) among those patients who reported first to traditional/spiritual healers like "Tebel", "Kalicha", church prayer and herbalist. However, statistically significant difference was not observed upon comparing this group with patients who first consulted other health care providers.

Upon patient's first presentation to a modern health care provider, $76.1 \%$ of symptomatic patients were first provided with non-anti-TB drugs, while sputum for AFB test was taken for only $14.7 \%$ of the symptomatic patients and $\mathrm{x}$-ray examination was done for $1 \%$ of these patients. The average health system delay for patients who received sputum or x-ray examination upon first arrival was 58.4 days (median of 44 days), while for those who didn't receive tuberculosis examination on arrival, average health system delay of 75 days (median 42 days) was reported. However, this difference was not statistically significant when examined with a nonparametric Mann-Whitney U-test $(\mathrm{P}=0.47)$.

The average number of the different types of health care providers that were visited till the start of anti-TB treatment was 2.64 (median=3). This was without taking into account the number of repeated visits made to the same health care provider. Table 3 shows the healthseeking pattern and clinical characteristics of the study subjects. Some characteristics of the facilities and the services provided at first presentation were also included.

\section{Distribution of delays}

Patient Delay: The rate of presentation to health care providers in this study was 24 per 1000 person-days of coughing in the community with median patient delay of 28 days (mean delay of 42.4 days). Patient delay has contributed $37 \%$ to the overall total delay to treatment. However, only $38.1 \%$ of patients were able to report within the first three weeks (acceptable delay) after developing symptoms of pulmonary tuberculosis. The distribution of the different components of delay is summarized in Table 4.

Health System delay: Health system delay in our context was the time ranging from patient's first contact to any modern health facility to date of commencement of AntiTB treatment. This comprises time spent during referrals between facilities, diagnosis and time between diagnosis and start of treatment and time spent on treatment of patients with drugs other than that for tuberculosis. Generally, median total health system delay of 42 days (mean $=72.2$ days) was reported in this study, making rate of 14 per 1000 person days of actively seeking diagnosis and then treatment. Sixty-three percent of total delay was contributed by health system delay. The last diagnosing facility delay contributed $7.9 \%$ to the total health system delay, while days spent after tuberculosis diagnosis (treatment delay) contributed $3.2 \%$ to health system delay. 
Table 2: Mean and median patient and health system delays across the different levels of patient characteristics in East Wollega Zone, April 2006

\begin{tabular}{|c|c|c|c|c|c|c|}
\hline \multirow[t]{2}{*}{ Variables } & \multirow[t]{2}{*}{$\mathbf{n}$} & \multirow[t]{2}{*}{$\%$} & \multicolumn{2}{|c|}{$\begin{array}{l}\text { Patient Delay } \\
\text { (in days) }\end{array}$} & \multicolumn{2}{|c|}{$\begin{array}{l}\text { Health system delay } \\
\text { (in days) }\end{array}$} \\
\hline & & & Mean & Median & Mean & Median \\
\hline \multicolumn{7}{|l|}{ Age (in year) } \\
\hline $15-25$ & 88 & 44.7 & 45.55 & 27 & 56.08 & 33 \\
\hline $26-35$ & 53 & 26.9 & 38.94 & 28 & 98.47 & 54 \\
\hline $36-45$ & 26 & 13.2 & 43.54 & 28 & 81.32 & 52 \\
\hline$>45$ & 30 & 15.2 & 38.53 & 29 & 65.17 & 41 \\
\hline \multicolumn{7}{|l|}{$\operatorname{Sex}(N=197)$} \\
\hline Male & 86 & 43.7 & 31.16 & 22 & 88.86 & 62 \\
\hline Female & 111 & 56.3 & 51.17 & 30 & 59.28 & 35 \\
\hline \multicolumn{7}{|l|}{ Place of residence (Area) } \\
\hline Rural & 106 & 53.3 & 51.32 & 30 & 85.59 & 49.5 \\
\hline Urban & 91 & 46.2 & 32.09 & 24 & 56.59 & 38 \\
\hline \multicolumn{7}{|l|}{$\begin{array}{l}\text { Cash income (in birr) } \\
(\mathrm{N}=155)\end{array}$} \\
\hline$\leq 70$ & 40 & 25.8 & 47.25 & 30 & 121.55 & 91 \\
\hline $70.01-150$ & 37 & 23.9 & 38.51 & 28 & 64.11 & 42 \\
\hline $151.01-220$ & 39 & 25.2 & 31.95 & 22 & 54.54 & 44 \\
\hline$>220$ & 39 & 25.2 & 29.97 & 25 & 63.08 & 39 \\
\hline \multicolumn{7}{|l|}{ Education } \\
\hline Non literate & 102 & 52.04 & 48 & 30 & 80 & 45 \\
\hline Grade 1-6 & 29 & 52.04 & 42 & 25 & 69 & 45 \\
\hline Grade 7-12 & 57 & 14.80 & 36 & 22 & 60 & 36 \\
\hline 12 and above & 8 & 29.08 & 22 & 20 & 70 & 74 \\
\hline \multicolumn{7}{|l|}{ Knowledge about TB } \\
\hline Unsatisfactory knowledge & 36 & 18.5 & 51.36 & 30 & 80 & 52 \\
\hline Fair (average) Knowledge & 134 & 68.8 & 40.10 & 28 & 71.88 & 39 \\
\hline Enough knowledge & 25 & 12.8 & 37.80 & 28 & 59.84 & 45 \\
\hline \multicolumn{7}{|l|}{ Stigma associated with TB } \\
\hline No stigma & 86 & 44.1 & 44 & 30 & 76 & 43 \\
\hline Some stigma & 103 & 52.8 & 42 & 25 & 66 & 39 \\
\hline Highly Stigmatized & 6 & 3.1 & 25 & 29 & 104 & 88 \\
\hline \multicolumn{7}{|l|}{ Sputum microscopy } \\
\hline $\mathrm{AFB}+$ & 95 & 48.2 & 43.04 & 28 & 86.94 & 58 \\
\hline AFB- & 102 & 51.8 & 41.87 & 28 & 58.47 & 38.5 \\
\hline $\begin{array}{l}\text { Disease severity on first } \\
\text { arrival }\end{array}$ & & & & & & \\
\hline Normal & 75 & 38.3 & 41.72 & 28 & 81.68 & 60 \\
\hline Mild to severe & 121 & 61.7 & 42.90 & 28 & 66.44 & 40 \\
\hline
\end{tabular}

Determinants of Patient Delay: In the final multivariate analyses for determinants of patient delay, only sex and area of residence were associated with patient delay and remain in the final Cox regression model (Likelihood Ratio $\mathrm{P}<0.05)$. Educational status and monthly income (that were significantly associated during Bivariate analyses) were not associated in determining how early the symptomatic patient reports to health care providers. Female patients and those patients from rural areas (both adjusted) tend to delay seeking care after noticing tuberculosis symptoms. Accordingly, female and rural patients were $37 \%$ and $46 \%$ less likely to report earlier than their male and urban counterparts, respectively (Table 5).

Determinants of Health system delay: In the Bivariate analyses, sex, area of residence and family income of the patient were found to affect the health system delay.
However, family income could not come significant to remain in the final model. Thus, patients from urban area had shorter health system delay than patients of rural area.

With regards to sex, female patients had shorter health system delay than their male counterpart after adjusting for area of residence. The opposite situation was observed in multivariate analysis for factors of patient delay where female patients consulted health facilities late. Table 6 indicates factors related to health system delay, both adjusted and unadjusted. 
Table 3: Health seeking pattern and clinical characteristics of pulmonary TB patients in East Wollega Zone, April 2006

\begin{tabular}{|c|c|c|}
\hline Sputum Microscopy for AFB & Frequency & Percent \\
\hline $\mathrm{AFB}+$ & 95 & 48.2 \\
\hline AFB- & 102 & 51.8 \\
\hline \multicolumn{3}{|l|}{ Patient category } \\
\hline New case & 182 & 92.4 \\
\hline Replace & 7 & 3.6 \\
\hline Transfer in & 1 & 0.5 \\
\hline Default & 7 & 3.6 \\
\hline \multicolumn{3}{|l|}{ Place of first presentation } \\
\hline Pharmacy/drug shop & 24 & 12.2 \\
\hline Private clinic/hospital & 46 & 23.4 \\
\hline Public clinic/HP & 34 & 17.3 \\
\hline Health center & 50 & 25.4 \\
\hline Public Hospital & 35 & 17.8 \\
\hline Traditional/spiritual & 8 & 4.1 \\
\hline \multicolumn{3}{|l|}{ Type of services obtained at first presentation } \\
\hline Referred to other level & 9 & 4.6 \\
\hline Advice only & 2 & 1.0 \\
\hline Other non Anti TB drug given & 150 & 76.1 \\
\hline Sputum taken for examination & 29 & 14.7 \\
\hline X-ray examination & 2 & 1.0 \\
\hline Admitted & 3 & 1.5 \\
\hline Other & 2 & 1.0 \\
\hline \multicolumn{3}{|c|}{${ }^{* *}$ Types of different health service providers contacts till start of Anti TB treatment } \\
\hline Only one type & 12 & 6.1 \\
\hline Two types & 80 & 40.6 \\
\hline More than 2 types & 105 & 53.3 \\
\hline \multicolumn{3}{|c|}{ Status of facilities that confirmed diagnosis of TB } \\
\hline Health Center & 33 & 16.8 \\
\hline Government Hospital & 160 & 81.2 \\
\hline Private Hospital & 4 & 2 \\
\hline \multicolumn{3}{|c|}{ Place of the diagnosing facility in reference to the patients Woreda } \\
\hline In the same Woreda & 88 & 44.7 \\
\hline Other Woreda in E. Wollega & 97 & 49.2 \\
\hline Out side E. Wollega Zone & 12 & 6.1 \\
\hline \multicolumn{3}{|c|}{ Major reasons for patient delay for more that 21 days as reported by patients } \\
\hline Assuming symptom will disappear by itself & 64 & 32.99 \\
\hline Financial constraints & 61 & 31.44 \\
\hline Health facility too far & 8 & 4.12 \\
\hline Work overload & 11 & 5.67 \\
\hline Absence of transportation & 14 & 7.22 \\
\hline Following traditional treatment & 4 & 2.06 \\
\hline Afraid of long processes in health facilities & 5 & 2.58 \\
\hline Other reasons ${ }^{\star \star \star}$ & 27 & 13.92 \\
\hline
\end{tabular}

** Doesn't include repeated visits patients made at one health provider

***Some other reasons mentioned were: Didn't believe health facilities had solution for the problem, didn't know where to get the services, very sick and not able to go to facilities, considered myself not sick

Table 4: Distribution of delays and rates to an event throughout the course of health seeking and start of treatment among pulmonary TB patients in East Wollega Zone, April 2006

\begin{tabular}{lcl}
\hline Type of Delay & Mean (Median) & Rates \\
\hline Total delay & $114.6(90)$ & $\begin{array}{l}9 \text { per } 1000 \text { person days of coughing } \\
24 \text { per1000 person days of coughing in the community } \\
\text { Patient delay }\end{array}$ \\
$\begin{array}{ll}42.44(28) \\
72.20(42)\end{array}$ & $\begin{array}{l}14 \text { per } 1000 \text { person days of actively seeking diagnosis and } \\
\text { then treatment } \\
176 \text { per } 1000 \text { person days of actively seeking diagnosis }\end{array}$ \\
$\begin{array}{l}\text { Last Diagnosing facility delay } \\
\text { Treatment delay }\end{array}$ & $2.68(3)$ & $\begin{array}{l}435 \text { per } 1000 \text { person days of actively seeking Rx after TB } \\
\text { diagnosis }\end{array}$ \\
\hline
\end{tabular}

${ }^{* *}$ Done only for patients first contacted Modern health service providers 
Table 5: Risk factors for patient delay, both adjusted and Unadjusted Hazard ratios and $95 \% \mathrm{Cl}$ in pulmonary TB patients, East Wollega Zone, April 2006

\begin{tabular}{|c|c|c|c|c|c|}
\hline \multirow{3}{*}{ Factors } & \multicolumn{5}{|c|}{ Patient delay time (days) } \\
\hline & \multicolumn{3}{|c|}{ Unadjusted } & \multicolumn{2}{|c|}{ Adjusted* } \\
\hline & $\mathbf{n}$ & Hazard ratio $(95 \% \mathrm{Cl})$ & $\mathbf{P}$ & Hazard ratio $(95 \% \mathrm{Cl})$ & $\mathbf{P}$ \\
\hline \multicolumn{6}{|l|}{ Sex } \\
\hline Male & 86 & Reference & & & \\
\hline Female & 111 & $0.6(0.45,0.8)$ & 0.001 & $0.63(0.47,0.84)$ & 0.002 \\
\hline \multicolumn{6}{|l|}{ Place } \\
\hline Rural & 106 & Reference & & & \\
\hline Urban & 91 & $1.55(1.162,2.066)$ & 0.003 & $1.46(1.1,1.95)$ & 0.010 \\
\hline Education & & & $0.003^{t}$ & & $0.074^{\mathrm{LRT}}$ \\
\hline Non literate & 91 & Reference & & & \\
\hline Read/write & 11 & $1.24(0.66,2.33)$ & 0.504 & $1.24(0.69,2.45)$ & 0.41 \\
\hline$(1-6)$ & 29 & $1.16(0.77,1.77)$ & 0.477 & $1.16(0.70,1.63)$ & 0.77 \\
\hline$(7-8)$ & 21 & $0.92(0.57,1.50)$ & 0.742 & $0.92(0.46,1.24)$ & 0.27 \\
\hline$(9-12)$ & 36 & $2.07(1.39,3.09)$ & 0.000 & $2.07(1.04,2.41)$ & 0.03 \\
\hline$>12$ & 8 & $2.43(1.17,5.07)$ & 0.018 & $2.43(0.95,4.23)$ & 0.07 \\
\hline Family income & & & $0.018^{t}$ & & $0.801^{\mathrm{LRT}}$ \\
\hline$\leq 70$ Birr & 40 & Reference & & & \\
\hline $71-150$ & 37 & $1.74(1.097,2.76)$ & 0.019 & $1.58(0.98,2.54)$ & .060 \\
\hline $151-220$ & 39 & 2.08(1.307, 3.293) & 0.002 & $1.797(1.10,2.94)$ & .020 \\
\hline >220 Birr & 39 & $1.81(1.15,2.85)$ & 0.010 & $1.585(0.97,2.596)$ & .067 \\
\hline
\end{tabular}

*Adjusted was for sex and area of residence, ${ }^{\mathrm{t}} \mathrm{P}$ significant for trend,

${ }^{\mathrm{LRT}} \mathrm{P}$ value of Likelihood Ratio Test for inclusion of the variable in the model

Table 6: Risk factors for health system delay, both adjusted and Unadjusted Hazard ratios and $95 \% \mathrm{Cl}$ in pulmonary TB patients, East Wollega Zone, April 2006

**Health System Delay Times (days)

\begin{tabular}{|c|c|c|c|c|c|}
\hline \multirow[t]{2}{*}{ Factors } & \multirow[b]{2}{*}{$\mathbf{n}$} & \multicolumn{2}{|c|}{ Unadjusted } & \multicolumn{2}{|l|}{ Adjusted* } \\
\hline & & Hazard ratio $(95 \% \mathrm{Cl})$ & $\mathbf{P}$ & Hazard ratio $(95 \% \mathrm{Cl})$ & $\mathbf{P}$ \\
\hline Sex & 189 & & & & \\
\hline Male & 85 & Reference & & & \\
\hline Female & 104 & $1.47(1.09,1.98)$ & 0.011 & $1.51(1.12,2.04)$ & 0.007 \\
\hline Place & 189 & & & & \\
\hline Rural & 103 & Reference & & & \\
\hline Urban & 86 & $1.50(1.12,2.01)$ & 0.007 & $1.54(1.15,2.07)$ & 0.004 \\
\hline Family income & 151 & & $0.005^{t}$ & & $0.1^{L R T}$ \\
\hline$\leq 70$ birr & 39 & Reference & & & \\
\hline $\begin{array}{l}70.01-150 \\
150.01 \text { to } 220\end{array}$ & $\begin{array}{l}36 \\
37\end{array}$ & $\begin{array}{l}1.73(1.09,2.77) \\
2.06(1.28,3.30)\end{array}$ & $\begin{array}{l}0.021 \\
0.003\end{array}$ & $\begin{array}{l}1.56(0.96,2.54) \\
1.79(1.08,2.96)\end{array}$ & $\begin{array}{l}0.071 \\
0.024\end{array}$ \\
\hline$>220$ birr & 39 & $1.83(1.16,2.89)$ & 0.009 & $1.60(0.97,2.64)$ & 0.070 \\
\hline
\end{tabular}

${ }^{*}$ Adjusted was for sex and area of residence

${ }^{\star *}$ Did not include those subjects first contact traditional or spiritual healers

${ }^{\text {LRT }} \mathrm{P}$ value of Likelihood Ratio Test for inclusion of the variable in the model

\section{Discussion}

The current study focuses on comparing rates of seeking treatment and of diagnosis among patients with pulmonary tuberculosis, emphasizing the statistical distribution of events occurring through time and highlighting the total duration of infectiousness in the community. Approaches that take this into account may convey a more appropriate picture of delays than comparing medians and analyzing time variables in to categories.
This study confirms that there is a considerable delay between the onset of illness and the initiation of treatment among pulmonary tuberculosis patients in East Wollega Zone of Ethiopia. A substantial proportion of the total delay to treatment was attributed to health system delay, an important preventable period of infectiousness in the community caused probably by the failure of the recognized health services to diagnose tuberculosis among symptomatic individuals and start treatment. This finding is similar with other African studies (8-11) where the health system delay exceeds the

Ethiop.J.Health Dev. 2007;21(2) 
patient delay. The long health system delay may also reflect insufficient knowledge of the signs and symptoms of TB among the different types of health service providers. This could be substantiated by the fact that majority of patients with symptoms of tuberculosis were not examined correctly for tuberculosis or referred to diagnostic facilities upon their first arrival, rather most of them were given treatment for diseases other than tuberculosis (76.1\%). Another reason might be inadequacy of the clinical services to diagnose TB among symptomatic individuals in most of the health services.

It is also observed that the number of days of patient delay is still much longer than the "acceptable" duration of three weeks recommended by the World Health Organization for suspected tuberculosis cases (12). The duration of unacceptable level of patient delay observed in this study is consistent with previous studies in Ethiopia $(4,13-16)$ and several other countries $(5,8,9$, 17-22), where a delay of more than three weeks was reported.

The total delay to treatment (the combination of patient and health system delay) observed in this study is similar to the delays reported in other studies in sub-Saharan Africa: 12 weeks in Botswana (10) and Kampala (11), 16 weeks in Ghana (8), and 16-20 weeks in Kenya (23).

In this study area, the public health system is the common first choice of care for TB patients, with more than $60 \%$ of individuals presenting to a public health facility initially, similar to other studies in Ethiopia (13, $15,16)$ and elsewhere in Africa (5). However, the private practitioners had also considerable numbers of patients contacting them as first choice, indicating the importance of these sectors. In cases where TB was suspected, referral by these private providers should be considered.

On the other hand, most of the tuberculosis diagnosis $164(83.2 \%)$ was confirmed at hospital level rather than at health centers or clinics that are closer to the community. A similar situation was reported by another study from Ethiopia [13] where most of the diagnoses of tuberculosis was made in district hospitals. Though all of the health facilities included in this study were entitled to provide both diagnostic and treatment services, the participation of health centers was very limited in contributing to the case detection. This is unacceptable when we look at the fact that most of the patients $(90.1 \%)$ were following the current treatment in health centers after they are referred back from hospitals. And again, only 35 patients $(17.8 \%$ of total) made the hospitals as their first contact. This might also strengthen the finding that large proportion of total delay $(63 \%)$ observed in this study was attributed to health system delay.

No significant association was observed between choice of health providers (first contact) and all types of delays in this study, similar to a study in Amhara Region (16) but different from what is reported in Southern Ethiopia (15) where visit to traditional healers increased the delay to treatment.

As reported in Ethiopia $(14,15)$ and elsewhere in Africa, $(8,9,10,18,23)$, rural residence was a risk factor for late presentation and diagnosis. This may be explained by several factors, including poorer access to health care in rural areas, lack of training of lower level health professionals, lack of supervision of health staff at peripheral level and differences in education levels between rural and urban areas (9).

Similarly, female gender is also observed to affect the duration of patient delay. Consistent finding was reported from many countries in Africa and Asia (5, 8, 9, 20, 23, 24) where women tend to seek care lately compared to men. However, this was not observed in other studies done in Ethiopia $(4,13)$ and in Botswana (10), the Gambia (9) and Brazil (25).

It is clear that the socio-economic and cultural position of women may influence their opportunities and add constraints in resolving their health needs (26).

In contrary to patient delay, male gender was found to be associated with longer health system delay compared to female gender. Men may visit several types of health care providers due to their ability to afford and this may prolong the time they start treatment (health system delay.

However, there was no significant difference in the number of facilities visited between male and female in this study. The other possibility could be the late presentation of female patients (i.e. long patient delay) may have been associated with severe tuberculosis and thus enabling health workers to diagnose TB easily and start treatment. Though not statistically significant, more female than male patients presented with mild to severe disease at first contacted health facility. However, in other studies it was reported that female patients had longer health system delay $(8,19,27)$.

In conclusion, in this study, it was observed that both the patient and health system delay were higher than the acceptable level. Moreover, a substantial proportion of the total delay to treatment was attributed to health system delay. This is an important preventable period of infectiousness in the community caused by the failure of recognized health services to diagnose tuberculosis among symptomatic individuals. Facilities relatively nearer to the people were also contributing less in the process of case detection, while case detection is one of the strategies in the prevention and control of tuberculosis. The majority of TB patients in this study area did not present to health facilities early and/or if 
they presented, did not receive treatment on time and thus continued to serve as reservoirs of infection. Even though, patient delay was unacceptably longer for both men and women, men were more likely than women to access health services faster. Rural residence was also found to be a risk factor for prolonged patient and health system delay.

One area of vital importance in aiming to reduce delay in diagnosis among TB suspects is to improve TB investigation services and the referral of patients presenting with symptoms of TB at the primary health care level. The study highlights the importance of improving referral systems and access to diagnostic facilities for TB, at the same time it is important to improve access to DOTS treatment and there by reduce the transmission of TB in the community.

Promotion of a concerted effort to increase awareness of the signs and symptoms of TB in the general population and encouraging self-referral to health services is crucial to increase the passive case detection.

If the health system is more accessible to those in need, then TB suspects would probably make use of it more often, thus new approaches to make health services more accessible to those in greatest need (to the rural and the disadvantaged women) should be developed.

Conducting a well-designed study to identify the reasons why most health centers, where larger segments of the community is closer, were not involved in the diagnosis of tuberculosis might clearly show ways of improving the services in these facilities.

Studies like this can be conducted by national TB control programmes in a larger scale and could generate useful information to improve the quality of services and strengthen the primary health care units for control of tuberculosis.

\section{Acknowledgements}

This study was carried out with the financial support obtained from Jimma University. We would also sincerely acknowledge East Wollega Zonal Health Office for its willingness in facilitating conditions for data collection. Special thanks are forwarded to the study participants without whose consent and collaboration this study would not have been realized.

\section{References}

1. Disease prevention and control department. Manual: Tuberculosis and Leprosy Prevention and Control Team. $3^{\text {nd }}$ edition. MOH of Ethiopia, Addis Ababa, Ethiopia.2005.

2. Jochem K, Walley J. Determinants of the tuberculosis burden in populations. In: Porter JDH Grange JM, eds. Tuberculosis - an interdisciplinary perspective. London: Imperial College, 1999: pp 3348.

3. Auer C, Sarol J, Jr, Tanner M, Weiss M. Health seeking and perceived causes of tuberculosis among patients in Manila, Philippines. Tropical Medicine and International Health. 2000;5:648-56.

4. Demissie M, Lindtjorn B, Berhane Y. Patient and health service delay in the diagnosis of pulmonary tuberculosis in Ethiopia. BioMedCentral Public Health 2002;2:23.

5. Pronyk RM, Makhubele MB, Hargreaves JR, Tollman SM, Hausler HP. Assessing health seeking behaviour among tuberculosis patients in rural South Africa. International Journal of TB and Lung Disease. 2001;5:619-27.

6. World Health Organization. Treatment Of Tuberculosis: Guidelines For National Programmes. $3^{\text {rd }}$ edition. Geneva WHO, 2003. $\mathrm{WHO} / \mathrm{CDS} / \mathrm{TB} / 2003.313$

7. World Health Organization. Toman's Tuberculosis: Case detection, treatment, and monitoring Questions and Answers. $2^{\text {nd }}$ edition. Geneva, WHO, 2004.

8. Lawn SD, Afful B, Acheampong JW. Pulmonary tuberculosis: diagnostic delay in Ghanaian adults. International Journal of $\mathrm{TB}$ and Lung Disease. 1998;2(8):635-640.

9. Lienhardt C, Rowley J, Manneh K, Lahai G, Needham D, Milligan P et al. Factors affecting time delay to treatment in a tuberculosis control programme in a sub-Saharan African country: the experience of The Gambia. International Journal of TB and Lung Disease. 2001;5:233-9.

10. Steen TW, Mazonde GN. Pulmonary tuberculosis in Kweneng District, Botswana: delays in diagnosis in 212 smear positive patients. International Journal of TB and Lung Disease. 1998;2(8):627-634.

11. Mpungu S Kiwuwa, Karamagi Charles and Mayanja Kizza Harriet. Patient and health service delay in pulmonary tuberculosis patients attending a referral hospital: a cross-sectional study. BioMedCentral Public Health 2005; 5:122 doi:10.1186/1471-24585-122.

12. World Health Organization. Tuberculosis: Treatment Guidelines for National Tuberculosis Programmes. 2nd edition. Geneva, WHO, 1997.

13. Mengiste $M$ Mesfin, Tesfay $\mathrm{W}$ Tasew, Israel $\mathrm{G}$ Tareke, Yohannes $\mathrm{T}$ Kifle, Witten $\mathrm{H}$ Karen and Madeley J Richard. Delays and care seeking behavior among tuberculosis patients in Tigray of northern Ethiopia. Ethiopian Journal of Health Development 2005;19:7-12.

14. Madebp T, Lindtjorn B. Delay in Treatment of Pulmonary Tuberculosis: An Analysis of Symptom Duration Among Ethiopian Patients. MedGenMed. 1999;E6.

15. Alexis Cambanis, Mohammed A. et al. Rural poverty and delayed presentation to tuberculosis

Ethiop.J.Health Dev. 2007;21(2) 
services in Ethiopia. Tropical Medicine and International Health; 2005. Volume 10 Issue 4 pp 330, Blackwell Publishing Ltd.

16. Solomon Yimer, Gunnar Bjune, Getu Alene. Diagnostic and treatment delay among pulmonary tuberculosis patients in Ethiopia: a cross sectional study. BioMedCentral Infectious Diseases 2005;5:112 doi:10.1186/1471-2334-5-112.

17. Asch S, Leake B, Anderson R, Gelberg L. Why do symptomatic patients delay obtaining care for tuberculosis? Am.J.Respir.Crit Care Med. 1998;157:1244-8.

18. Wandwalo ER, Morkve O. Delay in tuberculosis case-finding and treatment in Mwanza, Tanzania. International Journal of TB and Lung Disease. 1999;4(2):133-138.

19. Altet Gomez MN, Alcaide MJ, Canela SJ, Mila AC, Jimenez Fuentes MA, Souza Galvao ML et al. [Pulmonary symptomatic tuberculosis' diagnostic delay study]. Arch.Bronconeumol. 2003;39:146-52.

20. Rajeswari R, Chandrasekaran V, Suhadev M, Sivasubramaniam S, Sudha G, Renu G. Factors associated with patient and health system delays in the diagnosis of tuberculosis in South India. International Journal of TB and Lung Disease. 2002;6:789-95.

21. Lewis KE, Stephens C, Shahidi MM, Packe G. Delay in starting treatment for tuberculosis in east London. Commun.Dis.Public Health 2003;6:133-8.
22. Needham DM, Foster SD, Tomlinson G, GodfreyFaussett P. Socio-economic, gender and health services factors affecting diagnostic delay for tuberculosis patients in urban Zambia. Tropical Medicine and International Health. 2001;6:256-9.

23. Aluoch JA, Babu Swai O, Edwards EA, et al. Study of case-finding for pulmonary tuberculosis in outpatients complaining of a chronic cough in a district hospital in Kenya. Am Rev Respir Dis 1984;129:915-920.

24. Ngamvithayapong J, Yanai H, Winkvist A, Diwan V. Health Seeking Behavior and Diagnosis for pulmonary tuberculosis in an HIV-epidemic mountainous area of Thailand. International Journal of TB and Lung Disease. 2001;5:1013-20.

25. Martinho APS dos Santos, et al. Risk factors for treatment delay in pulmonary tuberculosis in Recife, Brazil BioMedCentral Public Health 2005;5:25.

26. Rathgeber EM, Vlassoff C. Gender and tropical diseases: a new research focus. Social Science and Medicine 1993;40:55-65.

27. Lonnroth K, Thuong LM, Linh PD, Diwan VK. Delay and discontinuity - a survey of TB patients' search of a diagnosis in a diversified health care system. International Journal of $\mathrm{TB}$ and Lung Disease. 1999;3:992-100. 